\title{
Determinants of self-efficacy in patients with Parkinson's disease
}

\author{
Determinantes de autoeficacia en pacientes con enfermedad de Parkinson \\ Ingrid ESTRADA-BELLMANN', Jesús Daniel MELÉNDEZ-FLORES 1,2, Carlos Rodrigo CÁMARA-LEMARROY1,3,4, \\ Sergio Andrés CASTILLO-TORRES ${ }^{1}$
}

\begin{abstract}
Background: Self-efficacy is the individual's assessment of his or hers ability to compıete a specific task successfully and has been closely related to self-management and quality of life in several diseases. Objective: To investigate self-efficacy in a population of Parkinson's disease (PD) patients in Mexico and study the factors that are associated with this measure. Methods: We carried out a cross-sectional observational study involving patients with PD in an outpatient neurology clinic in Mexico, using the following instruments: Spanish version of the Chronic Disease Self-Efficacy Scale (CDSES), Quality of Life Questionnaire PDQ-8, Movement Disorders Society-Unified Parkinson's disease Rating Scale (MDS-UPDRS), Montreal Cognitive Assessment (MoCA), and Non-Motor Symptom Scale (NMSS). Clinical and demographic variables were also recorded. Results: We included 73 patients with a mean age of 65 years and most patients were male. Patients with lower CDSES scores ( $<7.75)$ had worse scores in MDS-UPDRS, NMSS, and PDQ-8 scales. CDSES scores were significantly correlated with MDS-UPDRS Part I $(r=-0.497, p=<0.001)$, Part II $(r=-0.271, p=0.020)$, Part III $(r=-0.304, p=<0.001), P D Q-8(r=-0.472$, $p=<0.001)$, and NMSS $(r=-0.504, p=<0.001)$. Furthermore, when assessing the simultaneous effect of covariates associated with CDSES score, only Mood/Apathy domain of NMSS was significant (beta $=-0.446, t=-3.807, p=0.012$ ). Conclusions: PD patients with lower selfefficacy scores had worse motor and non-motor symptomatology and quality of life. Mood/Apathy disorders were negatively associated with self-efficacy and contributed significantly to this measure.
\end{abstract}

Keywords: Parkinson Disease; Self Efficacy; Quality of Life; Mood Disorders; Cognition.

\section{RESUMEN}

Antecedentes: La autoeficacia es la autoevaluación de un individuo sobre su capacidad para completar una tarea con éxito y se ha relacionado con automanejo y calidad de vida en otras enfermedades. Objetivo: Investigar la autoeficacia en una población de pacientes con enfermedad de Parkinson (EP) en México y estudiar factores asociados con esta medida. Métodos: Realizamos un estudio observacional transversal con pacientes con EP en una clínica de neurología en México. Se registraron datos demográficos y escalas que evalúan la función motora (MDS-UPDRS), no motora (NMSS) y cognitiva (MoCA), así como la calidad de vida (PDQ-8). Para valorar autoeficacia se utilizó la versión en español de la Escala de autoeficacia de enfermedades crónicas (CDSES). Resultados: Se incluyeron 73 pacientes, con una edad media de 65 años y la mayoría eran hombres. Pacientes con puntajes CDSES más bajos (<7.75) tuvieron peores puntajes en las escalas MDS-UPDRS, NMSS y PDQ-8. Las puntuaciones de CDSES se correlacionaron significativamente con la escala MDS-UPDRS Parte I $(r=-0.497, p=<0.001)$, Parte II $(r=-0.271, p=0.020)$, Parte III $(r=-0.304, p=<0.001), P D Q-8(r=-0.472, p=<0.001), y N M S S(r=-0.504, p=<0.001)$. Al evaluar el efecto simultáneo de covariables asociadas con la escala CDSES, solo el dominio estado de ánimo/apatía del NMSS resultó significativo (Beta $=-0.449, t=-3.783, p=\langle 0.001$ ). Conclusiones: Los pacientes con menores puntajes de autoeficacia tienen peor calidad de vida y sintomatología motora y no motora. Los trastornos del estado de ánimo contribuyen negativamente a la autoeficacia.

Palabras clave: Enfermedad de Parkinson; Autoeficacia; Calidad de Vida; Trastornos del Humor; Cognición.

\footnotetext{
1Universidad Autónoma de Nuevo León, Hospital Universitario “Dr. José E. González”, Servicio de Neurología, Monterrey, Nuevo León, México.

2Universidad Autónoma de Nuevo León, Facultad de Medicina, Monterrey, Nuevo León, México.

${ }^{3}$ University of Calgary, Department of Clinical Neurosciences, Cumming School of Medicine, Calgary, Canada.

uUniversity of Calgary, Hotchkiss Brain Institute, Cumming School of Medicine, Calgary, Canada.

IEB (1) https://orcid.org/0000-0002-7812-0462;JDMF (10 https://orcid.org/0000-0001-5252-3637;

CRCL (1D https://orcid.org/0000-0003-0676-6675; SACT (1D) https://orcid.org/0000-0002-4727-2535

Correspondence: Ingrid Estrada-Bellmann; Email: ingridestmann@hotmail.com.

Conflict of interest: The authors have no conflict of interest to report.

Authors' contributions: IEB, CRCL: contributed to the conception and design of the work; IEB, JDMF, SACT: contributed to acquisition and analysis of data; IEB, SACT: contributed to drafting of manuscript; IEB, CRCL: contributed to revision for intellectually important content; IEB, JDMF, CRCL, SACT: review and approval of the final version of the work.

Received on April 30, 2020; Received in its final form on October 09, 2020; Accepted on October 15, 2020.
} 


\section{INTRODUCTION}

Parkinson's disease (PD) is a multisystem disorder, and besides the classical motor symptoms, patients also suffer from a variety of non-motor symptoms ${ }^{1}$. The burden of $\mathrm{PD}$ over patients' daily activities is significant and often contributes to a poor quality of life (QOL). Traditional treatment has focused on ameliorating motor-symptoms, but a more comprehensive approach is often needed to care for patients and their caregivers ${ }^{23}$. Self-management offers a way of helping people with chronic and neurodegenerative diseases to play an active role in managing their condition and could have an impact on QOL ${ }^{4,5}$.

Self-efficacy is a patient attribute that has received limited attention in PD. It may be defined as an individual's assessment of his or hers ability to complete a specific task successfully $^{6}$. In the context of disease management, it has been able to predict health behaviors in neurological diseases such as Alzheimer's disease and multiple sclerosis ${ }^{7.8}$. A recent study showed that general self-efficacy was independently associated with overall life satisfaction in patients with $\mathrm{PD}^{9}$, highlighting the importance of this attribute.

Before establishing if self-efficacy in PD could be successfully targeted in interventional studies, there is a need to study the factors that determine self-efficacy levels in this population. Determinants of self-efficacy have been studied in other populations, showing that depression and anxiety levels, occupational status, and age were associated with this measure. Moreover, these studies have shown that measurements specific of the disease affect self-efficacy ${ }^{10-12}$. This leads to hypothesize that motor and non-motor symptomatology in PD might contribute to this measure as well. In this study, we evaluated self-efficacy in a population of PD patients in Mexico and studied the factors that are associated with this measure.

\section{METHODS}

We conducted a cross-sectional observational study on consecutive patients with PD from our outpatient clinic at the Department of Neurology of the University Hospital Dr. José Eleuterio González, Monterrey, Mexico, recruited from October 2014 to January 2016. Diagnosis of PD was made by a neurologist with competence in movement disorders according to the UK PD Brain Bank Criteria. This study was approved by the ethics committee of our institution and all patients signed informed consent for inclusion in this study; the procedures were all in compliance with the Declaration of Helsinki. Besides standard assessment, a semi structured interview was used to obtain information on disease history and other sociodemographic data and all patients completed the non-motor symptoms scale for PD (NMSS) ${ }^{13}$, the Montreal
Cognitive Assessment (MoCA) $)^{14}$, the Parkinson's disease questionnaire-8 (PDQ-8) scale for QOL ${ }^{15}$, and the Movement Disorders Society-Unified Parkinson's Disease Rating Scale (MDS-UPDRS) ${ }^{16}$. Disease stage was evaluated per the Hoehn and Yahr (HY) staging. The HY grade was dichotomized as mildly impaired $(\leq 2)$ and moderately to severely impaired $(\geq 3)^{17}$.

\section{Self-efficacy analysis}

For evaluation of self-efficacy in our population, we used the Spanish version of Chronic Disease Self-Efficacy Scale (CDSES), a 4-item scale developed and tested in the Chronic Disease Self-Management study, with an alpha coefficient of 0.85 and a test-retest validity of $0.80^{18}$. This scale assesses the individual's confidence in managing fatigue (1), pain (2), emotional status (3), and other symptoms (4) related to the disease that interfere with intended activities. The minimum score in each item is 0 , which represents no confidence, and 10, which represents total or full confidence. The score for this scale is the mean of the four items. Higher scores indicate higher self-efficacy.

\section{Statistical analysis}

All statistical analyses were performed using the SPSS computer program (SPSS version 23.0; SPSS Inc., Chicago, Illinois, United States). Data was tested for normality using the Kolmogorov-Smirnov test, and continuous variables were thus expressed as mean \pm standard deviation (SD) or as median (interquartile range, IQR), and categorical variables were expressed as percentages. For the bivariate analysis, CDSES scores were divided into low and high scores based on the median value of the scale for this population, as it followed a non-parametric distribution. Thus, all scores in the CDSES $\geq 7.75$ were considered as high, and scores $<7.75$ as low. Quantitative data were analyzed using student's $\mathrm{T}$ test or Mann-Whitney U-test, as appropriate. Categorical variables (expressed as percentages) were assessed using Chi-square or Fisher exact test.

Simple correlation analysis (using Pearson's or Spearman tests as appropriate) were used to evaluate the direction and strength of the relationship between CDSES and variables that showed significance in bivariate analysis. Multiple linear regression analysis was conducted to assess the simultaneous effect of covariates associated with CDSES scores. Independent variables included in the analysis were those that showed significance in the bivariate analysis. Multicollinearity was assessed using variation inflation factors (VIFs). Covariables with VIFs value $>5$ were excluded from the analysis. $R$ squared $\left(\mathrm{R}^{2}\right)$ was used to assess goodness of fit. A p value $<0.05$ was considered as statistically significant. 


\section{RESULTS}

\section{Population characteristics}

We included 73 patients, with a mean age of $65.6 \pm 11.6$ years. Of this population, 24 patients were female (33\%) and $49(67 \%)$ were male. The median years of schooling was 9 (6-12) years, whereas median years with diagnosis was 8 (6-13) years. Regarding comorbidities, frequencies of type 2 diabetes mellitus, hypertension, and dyslipidemia were $11.4 \%, 19.0 \%$, and $5.7 \%$, respectively. Median total CDSES was 7.75 (6-8.75). Median total MDS-UPRDS score was 60 (39-93) while median NMSS, PDQ-8, and MoCA scores were 37 (1461), 25 (13-44), and 26 (22-28), respectively.

\section{Bivariate analysis}

When comparing patients with low versus high CDSES scores, no significant differences in age, sex, years of schooling, and years with diagnosis were observed. Patients with low CDSES scores had significantly worse scores in MDS-UPDRS, NMSS, and PDQ-8 compared to patients with high CDSES scores. HY stage distribution was different between groups, showing a higher prevalence of lower grades (1-2) in patients with high CDSES values. No difference was observed between groups in MoCA scores (Table 1). Among the non-motor symptomatology, worse scores in Mood/ Apathy, Sleep/Fatigue, and Miscellaneous domains were observed in patients with low CDSES scores. No difference in scores was observed among other NMSS domains between groups (Table 2).

\section{Correlation analysis}

CDSES scores were significantly correlated with MDSUPDRS Part I ( $\mathrm{r}=-0.497, \mathrm{p}=<0.001)$, MDS-UPDRS Part II $(\mathrm{r}=$ -0.271, $\mathrm{p}=0.020)$, MDS-UPDRS Part III $(\mathrm{r}=-0.304, \mathrm{p}=<0.001)$,

Table 1. Differences between patients by CDSES scores.

\begin{tabular}{|c|c|c|c|}
\hline & Low CDSES scores $(n=35)$ & High CDSES scores $(n=38)$ & $\mathrm{p}$ \\
\hline Age (mean $\pm S D)$ & $66.5 \pm 10.9$ & $65.1 \pm 12.2$ & 0.636 \\
\hline Sex (male,\%) & $21(60)$ & $28(73)$ & 0.565 \\
\hline Years of education, median (IQR) & $9(6-12)$ & $9(6-12)$ & 0.471 \\
\hline Years since diagnosis, median (IQR) & $10(6-14)$ & $7(6-11)$ & 0.090 \\
\hline NMSS, median (IQR) & $60(32-99)$ & $20(10-39)$ & $<0.001$ \\
\hline PDQ-8, median (IQR) & $38(20-55)$ & $16(9-28)$ & 0.012 \\
\hline MoCA, median (IQR) & $26(21-28)$ & $25(22-28)$ & 0.916 \\
\hline MDS-UPDRS Total, median (IQR) & $89(54-105)$ & $48(35-65)$ & 0.001 \\
\hline MDS-UPDRS Part I, median (IQR) & $15(8-19)$ & $5(3-9)$ & $<0.001$ \\
\hline MDS-UPDRS Part II (mean \pm SD) & $16.9 \pm 9.3$ & $10.1 \pm 8.1$ & 0.008 \\
\hline MDS-UPDRS Part III (mean \pm SD) & $47.7 \pm 20.5$ & $34.2 \pm 19.2$ & 0.007 \\
\hline MSD-UPDRS Part IV, median (IQR) & $3(0-7)$ & $0(0-3)$ & 0.006 \\
\hline HY stage & & & 0.028 \\
\hline $1-2(\%)$ & $16(46)$ & $27(71)$ & \\
\hline $3-5(\%)$ & 19(54) & $11(29)$ & \\
\hline
\end{tabular}

CDSES: Chronic Disease Self-Efficacy Scale; NMSS: Non motor symptoms scale; PDQ-8: Parkinson's disease questionnaire 8; MoCA: Montreal Cognitive Assessment Scale; MDS-UPDRS: Movement Disorders Society Unified Parkinson's Disease Rating Scale; SD: Standard deviation; IQR: Interquartile range.

Table 2. Comparison of NMSS domains between patients by CDSES scores.

\begin{tabular}{lccc}
\hline Domains & $\begin{array}{c}\text { Low CDSES } \\
\text { scores }(n=35)\end{array}$ & $\begin{array}{c}\text { High CDSES } \\
\text { scores }(n=38)\end{array}$ & 0.122 \\
\hline Cardiovascular, median (IQR) & $2(0-4)$ & $0(0-2)$ & 0.004 \\
Sleep/Fatigue, median (IQR) & $12(6-19)$ & $4(2-9)$ & 0.001 \\
Mood/Apathy, median (IQR) & $10(2-22)$ & $2(0-4)$ & 0.640 \\
Perceptual Problems, median(IQR) & $0(0-1)$ & $1(0-3)$ & 0.239 \\
Attention/Memory, median(IQR) & $3(0-8)$ & $1(0-4)$ & 0.258 \\
Gastrointestinal, median (IQR) & $2(0-9)$ & $1(0-4)$ & 0.640 \\
Urinary, median (IQR) & $2(0-9)$ & $0(0-2)$ & 0.813 \\
\hline Sexual function, median (IQR) & $0(0-16)$ & $0(0-2)$ & 0.002 \\
\hline Miscellaneous, median (IQR) & $9(1-19)$ & & \\
\hline
\end{tabular}

NMSS: Non-motor symptom scale; CDSES: Chronic Disease Self-Efficacy Scale; IQR: interquartile range. 
PDQ-8 ( $\mathrm{r}=-0.472, \mathrm{p}=<0.001)$, NMSS total score $(\mathrm{r}=-0.504$, $\mathrm{p}=<0.001)$, NMSS Sleep/Fatigue domain $(\mathrm{r}=-0.380, \mathrm{r}=0.001)$, NMSS Miscellaneous domain ( $\mathrm{r}=-0.351, \mathrm{p}=0.002)$, and NMSS Mood/Apathy domain ( $r=-0.560, p=<0.001)$.

\section{Multiple regression analysis}

The multiple linear regression analysis adjusted by disease severity stage (HY) showed that only NMSS Mood/
Apathy domain remained a significant contributor to CDSES scores (beta $=-0.449, t=-3.783, \mathrm{p}=<0.001$ ). The model (shown in Table 3), which included MDS-UPDRS Part I, II, III, and IV scores, and the NMSS domains Mood/Apathy, Miscellaneous, and Sleep/Fatigue, explained $40 \%$ of the variance in CDSES scores, of which NMSS Mood/Apathy domain contributed with $30 \%$.

Table 3. Multivariate analysis of factors affecting CDSES scores in PD patients adjusted by disease stage.

\begin{tabular}{lccc}
\hline Variable & Beta & $t$ & $P$ \\
\hline MDS-UPDRS Part I & -0.216 & -1.405 & 0.156 \\
MDS-UPDRS Part II & 0.169 & 1.066 & 0.290 \\
\hline MDS-UDRS Part III & -0.196 & -1.341 & 0.185 \\
MDS-UPDRS Part IV & -0.024 & -0.215 & 0.831 \\
NMSS Mood/Cognition Domain & -0.449 & -3.783 & $<0.001$ \\
NMSS Miscellaneous Domain & -0.134 & -1.355 & 0.180 \\
NMSS Sleep/Fatigue Domain & 0.004 & 0.031 & 0.895 \\
\hline
\end{tabular}

CDSES: Chronic Disease Self-Efficacy Scale; PS: Parkinson's disease; MDS-UPDRS: Movement Disorder Society Unified Parkinson's Disease Rating Scale; NMSS: Non motor symptoms scale.

\section{DISCUSSION}

In this study, we found that patients with lower CDSES scores have worse scores in MDS-UPDRS, NMSS, and PDQ-8 scales. In addition, CDSES scores were significantly and negatively correlated to MDS-UPDRS Part I-III, NMSS Sleep/ Fatigue, Miscellaneous, and Mood/Apathy domains, and PDQ-8 scores. Furthermore, when assessing the simultaneous effect of covariates associated with CDSES score, only Mood/Apathy domain of NMSS was significant.

The finding that non-motor symptoms, especially mood/ apathy, contribute significantly to self-efficacy compared to motor symptomatology supports other studies that show a greater impact of non-motor symptoms towards healthrelated outcomes in PD patients ${ }^{19-21}$. These symptoms are highly prevalent and exhibit the involvement of other neurotransmitters aside from dopamine, as well as other systems, based on a caudal-rostral progression hypothesis ${ }^{22}$, where non-motor symptoms like hyposmia, constipation, and REM sleep behavior disorders may precede motor symptomatology for several years ${ }^{23-24}$, explaining the shift in research focus to the early diagnosis and treatment.

Worse QOL in patients with lower self-efficacy scores in this study might support the idea that these two measurements are closely related, as other studies evaluating self-efficacy and QOL have shown similar results, demonstrating a direct relation exists between these measures ${ }^{25,26}$. This relationship highlights the importance of assessing determinants for self-efficacy in this population, as more focus has been attributed to QOL in PD treatment ${ }^{27}$.
Few studies have evaluated self-efficacy in PD. In a study of 251 persons with PD, self-efficacy was found to be positively associated with a high life satisfaction, even after adjusting for disease stage ${ }^{9}$. Another concept that has been associated with this attribute is self-management. Patients with PD who have higher self-efficacy are able to manage better their symptoms and have a greater sense of support from family and others ${ }^{28}$. On the other hand, self-efficacy and psychosocial wellbeing are often positively correlated ${ }^{8}$. This could partly explain why mood/apathy domain from NMSS contributed significantly to self-efficacy scores in this study.

Various studies in other populations have focused on assessing the relationship between mood disorders and selfefficacy, where a correlation between these measures has been demonstrated ${ }^{29-32}$. Interestingly, the approach to understanding this association has been bidirectional, as mood disorders, especially depressive symptoms, might contribute to lower self-efficacy as these are related to greater stress generation and unfulfillment of tasks ${ }^{33}$, whereas a lack of selfefficacy might lead to depressive symptoms related to expectations of poor control over ones' life ${ }^{34}$. Our study found a significant negative correlation between these variables, and the importance of this finding lies in potential implementation of therapies that improve self-efficacy and in doing so, decrease the burden of mood disorders. In this manner, interventions aimed at improving self-efficacy could be essential in PD care at all stages of the disease, but more rigorous studies in this area are needed.

This study had some important limitations, commonly associated with a cross-sectional design. Our sample size was 
small, and the age and gender characteristics of our population might not be representative of the most common epidemiological characteristics of PD patients in general. Also, we used a single measure of cognitive function. Another important limitation is the lack of a formal evaluation for mood disorders in PD patients, considering the relationship between these and self-efficacy, and the findings of our study. Therfore, studies in larger populations are needed to establish the role self-efficacy has in affecting QOL, where addition of a formal evaluation of mood disorders would further support our findings.

In conclusion, self-efficacy is an attribute that should be further assessed in PD patients, considering its correlation with motor and non-motor symptomatology and quality of life. Mood disorders are important contributors to low selfefficacy, thus representing an opportunity for therapeutic interventions.

\section{REFERENCES}

1. Chaudhuri KR, Odin P, Antonini A, Martinez-Martin P. Parkinson's disease: the non- motor issues. Parkinsonism Relat Disord. $2011 \mathrm{Dec}$ 1;17(10):717-23. https://doi.org/10.1016/j.parkreldis.2011.02.018

2. Uitti RJ. Treatment of Parkinson's disease: focus on quality of life issues. Parkinsonism Relat Disord. 2012 Jan 1;18 Suppl 1:S34-6. https://doi.org/10.1016/S1353-8020(11)70013-X

3. Martinez-Martin P. The importance of non-motor disturbances to quality of life in Parkinson's disease. J Neurol Sci. 2011 Nov 15;310(12):12-6. https://doi.org/10.1016/j.jns.2011.05.006

4. Lee C-N, Kim M, Lee HM, Jang J-W, Lee S-M, Kwon DY, et al. The interrelationship between non-motor symptoms in Atypical Parkinsonism. J Neurol Sci. 2013 Apr 15;327(1-2):15-21. https://doi. org/10.1016/j.jns.2013.01.034

5. Li H, Zhang M, Chen L, Zhang J, Pei Z, Hu A, et al. Nonmotor symptoms are independently associated with impaired healthrelated quality of life in Chinese patients with Parkinson's disease. Mov Disord. 2010 Dec 15;25(16):2740-6. https://doi.org/10.1002/ mds. 23368

6. Bandura A. Self efficacy: the exercise of control. New York (NY): Freedman Press; 1997. 604p.

7. Quinn C, Toms G, Anderson D, Clare L. A review of self-management interventions for people with Dementia and Mild Cognitive Impairment. J Appl Gerontol. 2016 Nov;35(11):1154-88. https://doi. org/10.1177/0733464814566852

8. Eccles FJR, Simpson J. A review of the demographic, clinical and psychosocial correlates of perceived control in three chronic motor illnesses. Disabil Rehabil. 2011 Sep 23;33(13-14):1065-88. https:// doi.org/10.3109/09638288.2010.525287

9. Rosqvist K, Hagell P, Odin P, Ekström H, Iwarsson S, Nilsson MH. Factors associated with life satisfaction in Parkinson's disease. Acta Neurol Scand. 2017 Jul;136(1):64-71. https://doi.org/10.1111/ ane.12695

10. Maly MR, Costigan PA, Olney SJ. Determinants of self efficacy for physical tasks in people with knee osteoarthritis. Arthritis Rheum. 2006 Feb 15;55(1):94-101. https://doi.org/10.1002/art.21701

11. Rahman A, Ambler G, Underwood MR, Shipley ME. Important determinants of self-efficacy in patients with musculoskeletal pain. J Rheumatol. 2004 Jun;31(6):1187-92.

12. Kahraman BO, Savci S, Ozsoy I, Acar S, Ozpelit E, Sevinc C, et al. Determinants of self-efficacy in patients with pulmonary arterial hypertension: a pilot study. Eur Respir J. 2016 Nov 8;48 Suppl 60:PA4436. https://doi.org/10.1183/13993003.congress-2016. PA4436

13. Martinez-Martin P, Rodriguez-Blazquez C, Abe K, Bhattacharyya KB, Bloem BR, Carod-Artal FJ, et al. International study on the psychometric attributes of the non-motor symptoms scale in Parkinson disease. Neurology. 2009 Nov 10;73(19):1584-91. https:// doi.org/10.1212/WNL.0b013e3181c0d416

14. Hoops S, Nazem S, Siderowf AD, Duda JE, Xie SX, Stern MB, et al. Validity of the MoCA and MMSE in the detection of $\mathrm{MCl}$ and dementia in Parkinson disease. Neurology. 2009 Nov 24;73(21):1738-45. https://doi.org/10.1212/WNL.0b013e3181c34b47

15. Jenkinson C, Fitzpatrick R, Peto V, Greenhall R, Hyman N. The PDQ-8: development and validation of a short-form parkinson's disease questionnaire. Psychol Health. 1997;12(6):805-14. https://doi. org/10.1080/08870449708406741

16. Martinez-Martin P, Rodriguez-Blazquez C, Alvarez-Sanchez M, Arakaki T, Bergareche-Yarza A, Chade A, et al. CG. Expanded and independent validation of the Movement Disorder Society-Unified Parkinson's Disease Rating Scale (MDS-UPDRS). J Neurol. 2013 Jan;260(1):228-36. https://doi.org/10.1007/s00415-012-6624-1

17. Martinez-Martin P, Skorvanek M, Rojo-Abuin JM, Gregova Z, Stebbins GT, Goetz CG. Validation study of the hoehn and yahr scale included in the MDS-UPDRS. Mov Disord. 2018 Apr;33(4):651-2. https://doi. org/10.1002/mds.27242

18. Lorig KR, Ritter PL, González VM. Hispanic chronic disease selfmanagement: a randomized community-based outcome trial. Nurs Res. 2003 Nov-Dec;52(6):361-9. https://doi.org/10.1097/00006199200311000-00003

19. Hermanowicz N, Jones SA, Hauser RA. Impact of non-motor symptoms in Parkinson's disease: a PMDAlliance survey. Neuropsychiatr Dis Treat. 2019 Aug 5;15:2205-12. https://doi. org/10.2147/NDT.S213917

20. Berganzo K, Tijero B, González-Eizaguirre A, Somme J, Lezcano E, Gabilondo I, et al. Motor and non-motor symptoms of Parkinson's disease and their impact on quality of life and on different clinical subgroups. Neurologia. 2016 Nov-Dec;31(9):585-91. https://doi. org/10.1016/j.nrl.2014.10.010

21. García DS, Fonticoba T de D, Castro ES, Borrué C, Mata M, Vila BS, et al. Non-motor symptoms burden, mood, and gait problems are the most significant factors contributing to a poor quality of life in nondemented Parkinson's disease patients: results from the COPPADIS study cohort. Parkinsonism Relat Disord. 2019 Sep;66:151-7. https:// doi.org/10.1016/j.parkreldis.2019.07.031

22. Braak H, Del Tredici K, Rüb U, de Vos RA, Steur ENHJ, Braak E. Staging of brain pathology related to sporadic Parkinson's disease. Neurobiol Aging. 2003 Mar-Apr;24(2):197-211. https://doi.org/10.1016/S01974580(02)00065-9

23. Munhoz RP, Moro A, Silveira-Moriyama L, Teive HA. Non-motor signs in Parkinson's disease: a review. Arq Neuropsiquiatr. 2015 May;73(5):454-62. https://doi.org/10.1590/0004-282X20150029

24. Schapira AHV, Chaudhuri KR, Jenner P. Non-motor features of Parkinson disease. Nat Rev Neurosci. 2017 Jul;18(7):435-50. https:// doi.org/10.1038/nrn.2017.62

25. Tonga JB, Eilertsen D-E, Solem IKL, Arnevik EA, Korsnes MS, Ulstein ID. Effect of self-efficacy on quality of life in people with mild cognitive impairment and mild dementia: the mediating roles of depression and anxiety. Am J Alzheimers Dis Other Demen. 2020 Jan-Dec;35:1533317519885264. https://doi. org/10.1177/1533317519885264 
26. Peters M, Potter CM, Kelly L, Fitzpatrick R. Self-efficacy and healthrelated quality of life: a cross-sectional study of primary care patients with multi-morbidity. Health Qual Life Outcomes. 2019 Feb 14;17(1):37. https://doi.org/10.1186/s12955-019-1103-3

27. Martinez-Martin P, Kurtis MM. Health-related quality of life as an outcome variable in Parkinson's disease. Ther Adv Neurol Disord. 2012 Mar;5(2):105-17. https://doi.org/10.1177/1756285611431974

28. Chenoweth L, Gallagher R, Sheriff JN, Donoghue J, Stein-Parbury J. Factors supporting self-management in Parkinson's disease: implications for nursing practice. Int J Older People Nurs. 2008 Sep;3(3):187-93. https://doi.org/10.1111/j.1748-3743.2008.00123.x

29. Craig A, Wijesuriya N, Tran Y. The influence of self-efficacy on mood states in people with Spinal Cord Injury. ISRN Rehabilitation. 2013;2013:232978. https://doi.org/10.1155/2013/232978

30. Ahmad ZR, Yasien S, Ahmad R. Relationship between perceived social self-efficacy and depression in adolescents. Iran J Psychiatry Behav Sci. 2014;8(3):65-74.
31. Parada P, Oliva M, Lázaro E, Amayra I, Paz JFL, Martínez O, et al. Anxiety, depression and self-efficacy in patients with Myasthenia Gravis. Int J Psychol Psychol Ther. 2014;14(1):105-13.

32. Tak YR, Brunwasser SM, Lichtwarck-Aschoff A, Engels RCME. The prospective associations between self-efficacy and depressive symptoms from early to middle adolescence: a cross-lagged model. J Yoth Adolesc. 2017 Apr;46(4):744-56. https://doi.org/10.1007/ s10964-016-0614-Z

33. Hammen CL. Stress generation in depression: reflections on origins, research, and future directions. J Clin Psychol. 2006 Sep;62(9):106582. https://doi.org/10.1002/jclp.20293

34. Bandura A. On the functional properties of perceived selfefficacy revisited. J Managet. 2012 Jan 1;38(1):9-44. https://doi. org/10.1177/0149206311410606 